\title{
The Effects of Temperature on Growth and Production of the Antibiotic Granaticin by a Thermotolerant Streptomycete
}

\author{
By P. D. A. JAMES* AND C. EDWARDS \\ Department of Genetics and Microbiology, Life Sciences Building, The University, \\ Liverpool L69 3BX, UK
}

(Received 2 November 1988; revised 16 February 1989; accepted 30 March 1989)

\begin{abstract}
The synthesis of granaticin, a polyketide-derived antibiotic synthesized as a secondary metabolite by Streptomyces thermoviolaceus strain NCIB 10076, was studied at different growth temperatures. Quantitative measurements of the antibiotic made during batch fermentations showed that the yield was greatest at $45^{\circ} \mathrm{C}$, whereas the rate of synthesis was most rapid at $37^{\circ} \mathrm{C}$. The timing of the appearance of granaticin in culture could not be assigned to any particular phase of growth or to de-repression due to depletion of any particular nutrient. However, at all temperatures, appearance of the antibiotic coincided with a rise in ammoniacal nitrogen presumably due to deamination of glutamate, the carbon source for growth. We have previously shown that production of the antibiotic is $\mathrm{pH}$ sensitive and that some carbon sources result in higher titres than others. This paper examines the effect of temperature on the physiology of growth and on antibiotic production in more detail under conditions that also allow an exact measurement of granaticin yield.
\end{abstract}

\section{INTRODUCTION}

Taxonomic studies have revealed that many Streptomyces are able to grow at $45^{\circ} \mathrm{C}$ (Williams et al., 1983). However until recently there were relatively few reports concerning the ability of species from this group to grow at temperatures in excess of $50^{\circ} \mathrm{C}$. Goodfellow et al. (1987) surveyed 50 thermophilic streptomycetes from a range of habitats which they were able to assign to a number of clusters in a numerical phenetic study that identified some features of their physiology and metabolic versatility. Such work is valuable in view of the commercial advantages of thermophilic species. These include faster reaction times and reduced cooling costs for large fermentations which make the thermophilic streptomycetes potentially useful vehicles for antibiotic production at high temperatures. Streptomyces thermoviolaceus is a particularly useful model system for such studies because it grows over a temperature range of around 25 to $58^{\circ} \mathrm{C}$ (Edwards \& Ball, 1987) and produces granaticin, a pigmented and $\mathrm{pH}$ sensitive antibiotic (Maehr et al., 1979) which is synthesized via the polyketide pathway (Arnone et al., 1979; Snipes et al., 1979). Snipes et al. (1979), using ${ }^{13} \mathrm{C}$-labelled acetate and glucose, showed that granaticin is produced by mixed biogenesis from eight acetate units and one dideoxyglucose moiety. This agrees with other radiolabelling work that showed polyketide antibiotics to be acetate derived (Floss et al., 1985). Using an ${ }^{18} \mathrm{O}_{2}$ atmosphere, Floss et al. (1985) also demonstrated that no molecular oxygen was incorporated into the molecule, indicating a direct cyclization of the polyacetyl chain rather than a classical hydroxylation using molecular oxygen, followed by a dehydration to the lactone.

\section{METHODS}

Organism and culture conditions. Streptomyces thermoviolaceus subsp. thermoviolaceus NCIB 10076 was maintained on complex solid medium that contained $\left(\mathrm{g}^{-1}\right)$ : glucose, 4 ; malt extract, 10 ; yeast extract, 4 ; and after adjusting to $\mathrm{pH} 7 \cdot 2$, agar, 20 . After $48-72 \mathrm{~h}$ incubation at $50^{\circ} \mathrm{C}$ the aerial mycelium bearing grey spores had 
formed and the spores were resuspended in $30 \%(\mathrm{v} / \mathrm{v})$ glycerol and stored at $-70{ }^{\circ} \mathrm{C}$. Defined salts medium contained ( $\left.\mathrm{g} \mathrm{l}^{-1}\right)$ : glutamate (sodium salt), 9.35; MOPS [3-( $N$ morpholino)propanesulphonic acid], 5.23; $\left(\mathrm{NH}_{4}\right)_{2} \mathrm{SO}_{4}, 2 ; \mathrm{MgSO}_{4} .7 \mathrm{H}_{2} \mathrm{O}, 1 ; \mathrm{K}_{2} \mathrm{HPO}_{4}, 1 ; \mathrm{CaCl}_{2} .2 \mathrm{H}_{2} \mathrm{O}, 0.05$ and $1 \mathrm{ml} \mathrm{l}^{-1}$ of a trace element solution that contained $1 \mathrm{~g} \mathrm{l}^{-1}$ of each of the following: $\mathrm{MnCl}_{2} \cdot 4 \mathrm{H}_{2} \mathrm{O}, \mathrm{ZnSO}_{4} \cdot 7 \mathrm{H}_{2} \mathrm{O}, \mathrm{FeSO}_{4} \cdot 7 \mathrm{H}_{2} \mathrm{O}$. The resultant solution was adjusted to $\mathrm{pH} 7.0$ prior to autoclaving for $15 \mathrm{~min}$ at $121^{\circ} \mathrm{C}$ and 15 p.s.i. $(103.5 \mathrm{kPa})$. Inocula were raised from spores by adding $1 \mathrm{ml}$ of spore suspension to $100 \mathrm{ml}$ of salts medium in $500 \mathrm{ml}$ flasks. These were incubated with shaking for $10,12,14,20$ or $24 \mathrm{~h}$ for the temperature series $55,50,45,37,30^{\circ} \mathrm{C}$ respectively after which time they were used to inoculate the fermenter (at the appropriate temperature).

Fermentations. These were carried out in an LH 500 series fermenter using a 2 litre vessel with a working volume of $1800 \mathrm{ml}$ and equipped with baffles and $\mathrm{pH}$ control to 7.0 using $1 \mathrm{M}-\mathrm{H}_{2} \mathrm{SO}_{4}$ as the titrant. Dissolved oxygen was monitored using an Ingold oxygen electrode (Ingold Electrodes, Wilmington, Massachusetts, USA) connected via a proportional/differential controller attached to the agitator such that stirring was between 500 and 1400 r.p.m. in order to keep dissolved oxygen tension above $108 \mathrm{nmol}$ oxygen $\mathrm{ml}^{-1}$. Oxygen uptake rates were measured periodically using the dynamic method, by briefly switching the automatic stirrer control to the minimum agitation rate and cutting off the air supply. The oxygen uptake rate was then calculated from the rate of dissolved oxygen consumption detected by an Ingold oxygen electrode probe linked to a chart recorder. Samples were removed at regular intervals during the growth period and the following analytical determinations carried out.

Measurements in culture samples. (a) Biomass determination. Culture samples $(25 \mathrm{ml})$ were harvested and pelleted by centrifugation at $1800 \mathrm{~g}$ for $10 \mathrm{~min}$ and the pellet washed with water, resuspended in $5 \mathrm{ml}$ of distilled water and placed in a pre-dried, pre-weighed foil cap and dried to constant mass at $105^{\circ} \mathrm{C}$ in an oven.

(b) Granaticin. Cell free supernatant $(25 \mathrm{ml})$ was lowered to $\mathrm{pH} 4.0$ using dilute $\mathrm{HCl}$ and then extracted twice in $0.5 \mathrm{vol}$. $(12.5 \mathrm{ml})$ of ethyl acetate, until no colour was visible in the aqueous phase. This was evaporated to dryness under vacuum, resuspended in a similar volume of ethyl acetate and dried again. The resulting residue was resuspended in $0.5 \mathrm{vol} .(12.5 \mathrm{ml})$ of $0.1 \mathrm{M}-\mathrm{HCl}$ made up in ethanol. The absorbance was then read, against a suitable blank, at $223 \mathrm{~nm}$ using a Perkin-Elmer Lambda-5 spectrophotometer and the concentration of the antibiotic calculated using the mM absorption coefficient calculated from the purified sample.

(c) Glutamate. This was measured in cell free supernatants prepared from different stages of growth using the Lglutamic acid colorimetric method supplied in kit form by Boehringer Mannheim (Ruf \& Siepe, 1983).

(d) Ammoniacal nitrogen determination. Cell free supernatants prepared from different stages of growth were analysed for ammoniacal nitrogen using the indolphenol colorimetric determination (Wainwright \& Pugh, 1973).

Purification of granaticin. The pH of 60 litres of whole broth that contained granaticin was adjusted to $\mathrm{pH} 4 \cdot 0$ using $\mathrm{HCl}$. The antibiotic was extracted twice using 30 litres of ethyl acetate until the aqueous layer was colourless. The extract was evaporated to dryness under vacuum and the residue taken up in 2 litres of alkaline water adjusted to $\mathrm{pH} 9$ with $\mathrm{NaOH}$. This was back extracted with $400 \mathrm{ml}$ of ethyl acetate to remove lipid residue left in the aqueous layer. Granaticin is relatively insoluble in ethyl acetate at $\mathrm{pH} 9$ and remains primarily in the aquous layer. The $\mathrm{pH}$ was again lowered to 4 and the granaticin extracted into 2 litres of ethyl acetate. This was evaporated to dryness, redissolved in a similar volume and again evaporated to remove the last traces of water. The remaining residue was then dissolved in $10 \mathrm{ml}$ of fresh ethyl acetate and hexane added until a precipitate was formed. This precipitate was filtered in a Buchner funnel under vacuum and washed twice with hexane to remove any remaining impurities. The resulting powder was then desiccated and stored for future use.

\section{RESULTS}

\section{Method for estimation of granaticin}

Before the effects of temperature on granaticin production could be assessed a reliable means of estimating the amount of antibiotic in culture samples was required. A spectrum of purified granaticin dissolved in acidified ethanol $(0.1 \mathrm{M}-\mathrm{HCl}$ in ethanol) is shown in Fig. 1. Peaks are apparent at 223, 285, 410, 490, 525 and $562 \mathrm{~nm}$ with the largest being at $223 \mathrm{~nm}$. From this spectrum, using an $M_{\mathrm{r}}$ value of 444.1 (St Pyrek et al., 1969), an absorption coefficient (mM) of 22.8 was calculated. This was used to determine the granaticin yields in all further work.

\section{Activities of cultures at low and high growth temperatures}

Fermentations were set up at different temperatures with glutamate as carbon source. Previous work had indicated that glutamate resulted in high titres of granaticin (James \& Edwards, 1988). This growth substrate could act as both the sole carbon and nitrogen source and supported growth and antibiotic production (results not shown). However, it was noted that inclusion of $\left(\mathrm{NH}_{4}\right)_{2} \mathrm{SO}_{4}$ in salts media containing glutamate did not result in lower yields of granaticin compared with glutamate alone. This indicates that, under these growth conditions, 


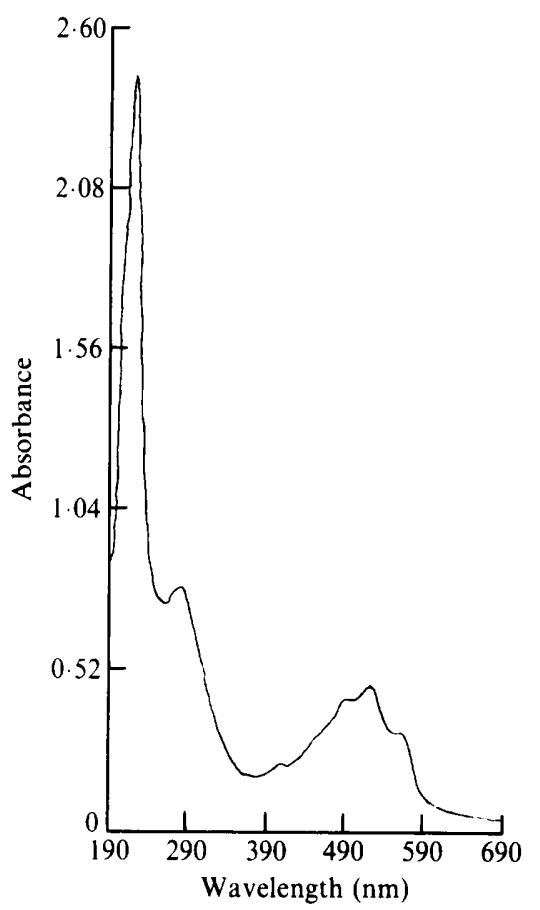

Fig. 1. Spectrum of purified granaticin. A known amount $(4.75 \mathrm{mg})$ of the antibiotic was dissolved in $100 \mathrm{ml}$ acidified ethanol and a spectrum of the resultant solution determined. The peak at $223 \mathrm{~nm}$ was used to calculate an absorption coefficient for granaticin.

antibiotic production is not repressed by ammoniacal nitrogen. This is unlike $S$. fradiae, which is stimulated to produce tylosin by glutamate, but inhibited by the presence of ammonia in the medium (Vu-Trong \& Gray, 1987). Two batch fermentations representative of a low $\left(30^{\circ} \mathrm{C}\right)$ and high $\left(50^{\circ} \mathrm{C}\right)$ growth temperature are shown in Figs $2(a)$ and $(b)$ respectively. Previous work has shown that with glutamate as carbon source, growth and secondary metabolism were accompanied by a rise in pH (James \& Edwards, 1988). This is due partly to the removal of glutamic acid and partly to the secretion of ammoniacal nitrogen into the medium. At $30^{\circ} \mathrm{C}$ biomass reached a maximum value of $3.7 \mathrm{~g} \mathrm{l}^{-1}$ after $55 \mathrm{~h}$, with a doubling time of around $4.2 \mathrm{~h}$ up to $26 \mathrm{~h}$, but thereafter growth slowed down. The cessation of the more rapid growth phase was accompanied by the appearance of granaticin in culture supernatants; its synthesis continued up to $50 \mathrm{~h}$ and then the level decreased with time. Respiratory rate, an indirect measure of growth, increased exponentially up to around $53 \mathrm{~h}$ but then declined at the same time as the apparant degradation of granaticin was occurring, but perhaps more significantly at the time when the carbon source had nearly been exhausted. Glutamate disappearance was also measured and it is noteworthy that at the time when the level of granaticin was maximal some $30 \%$ of the initial amount of glutamate remained unused. Ammoniacal nitrogen rose at approximately the same time as granaticin synthesis. The levels up to around $44 \mathrm{~h}$ remained constant at $15 \mathrm{mmol} \mathrm{l}^{-1}$, which was the concentration of ammonia initially supplied as $\left(\mathrm{NH}_{4}\right)_{2} \mathrm{SO}_{4}$ in the growth medium. This result indicates that under these cultural conditions $S$. thermoviolaceus meets its nitrogen requirement predominantly via the catabolism of glutamate (Fig. $2 a$ ).

At and above $50^{\circ} \mathrm{C}$ the overall trends in the different parameters tested (Fig. $2 b$ ) were the same as those described for the fermentation at $30^{\circ} \mathrm{C}$. The major differences were that the reaction times were much faster and granaticin production was greatest when the glutamate had been completely depleted. Growth at $50{ }^{\circ} \mathrm{C}$ was rapid and uninterrupted up to the peak biomass of $3.7 \mathrm{~g}^{-1}$ at $9 \mathrm{~h}$. The oxygen uptake rate increased with an identical gradient (Fig. $2 b$ ) until the peak biomass was reached, then dropped rapidly. The peak biomass coincided with substrate 

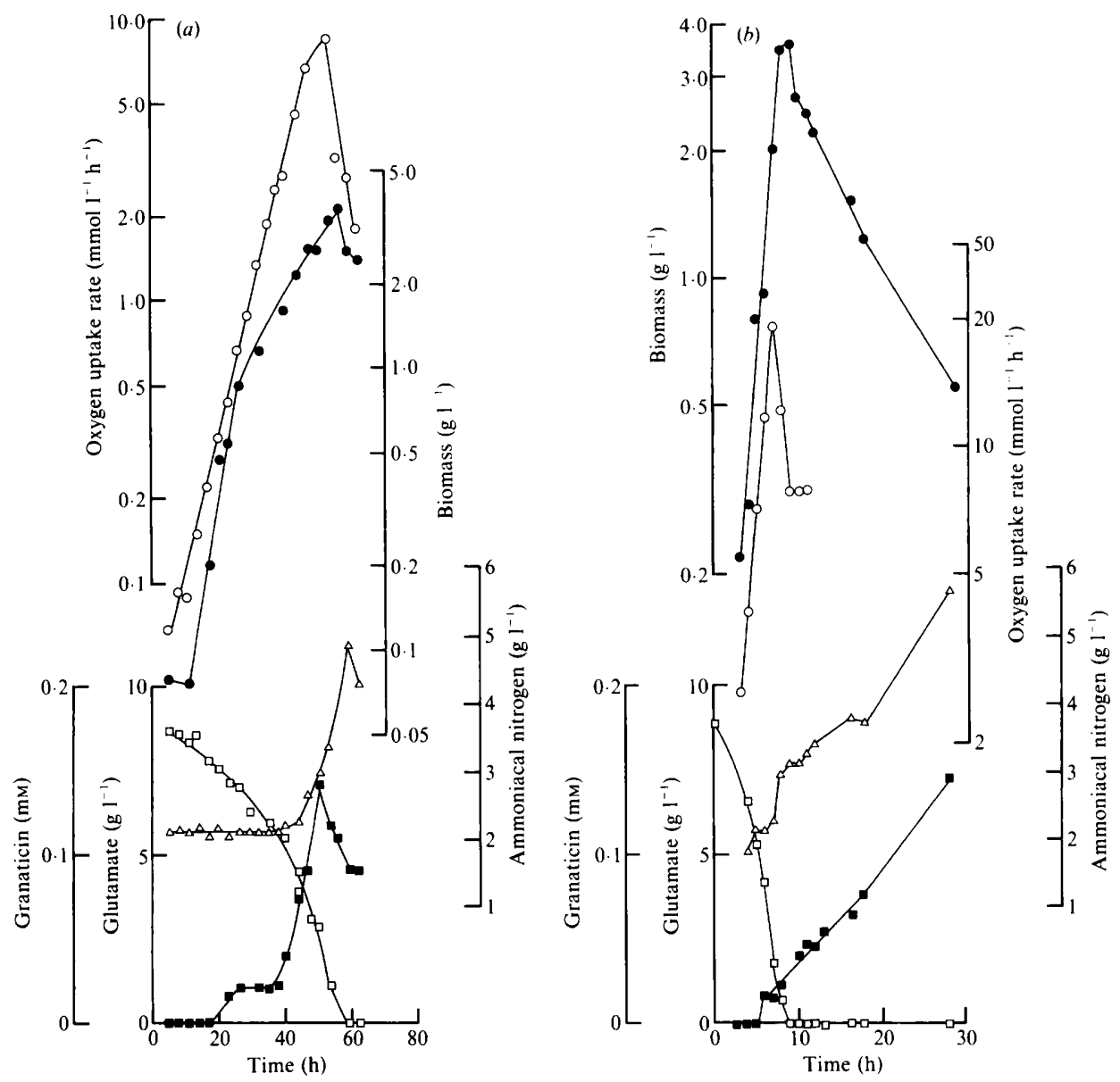

Fig. 2. Typical batch fermentations for $S$. thermoviolaceus grown at (a) $30^{\circ} \mathrm{C}$ or $(b) 50^{\circ} \mathrm{C}$ in a glutamate/salts medium. Samples were removed during growth in order to determine the amounts of biomass $(\bigcirc)$, glutamate $(\square)$, granaticin $(\square)$, and ammoniacal nitrogen $(\triangle)$. The in situ respiratory activity $(O)$ was also measured before removal of each sample.

exhaustion. Granaticin appeared after $6 \mathrm{~h}$ growth and its production continued well after all the carbon source had been consumed. At $30^{\circ} \mathrm{C}$ granaticin synthesis occurred when there was still an appreciable concentration of glutamate remaining (Fig. $2 a$ ). The ammoniacal nitrogen also followed antibiotic synthesis more closely at this temperature. Finally, it is noteworthy that once the carbon source had been completely utilized there was a rapid fall in biomass indicative of cell lysis.

\section{Effects of temperature on growth and antibiotic production}

Figs $3(a)$ and $(b)$ summarize the results for some of the parameters tested in Fig. $2(a)$ and $(b)$ for fermentations cultured at temperatures ranging from $30-55^{\circ} \mathrm{C}$. The generation time of $S$. thermoviolaceus grown at $30^{\circ} \mathrm{C}$ was approximately $4 \mathrm{~h}$ and fell with increasing incubation temperature to around $1 \mathrm{~h}$ at $50^{\circ} \mathrm{C}$. At $55^{\circ} \mathrm{C}$, which is near to the maximum temperature $\left(58^{\circ} \mathrm{C}\right)$ for growth, it rose to $3 \mathrm{~h}$, indicating that cellular metabolism was becoming thermosensitive. Yield of biomass decreased up to $45^{\circ} \mathrm{C}$, a temperature at which the yield of granaticin was at its highest. Conversely at $50^{\circ} \mathrm{C}$ the yield of biomass increased whilst that of granaticin fell from around $0.37 \mathrm{~mm}$ to $0.14 \mathrm{~mm}$ (Fig. $3 a$ ). Fig. $3(b)$ confirms that the optimum temperature for yield of antibiotic is $45^{\circ} \mathrm{C}$ whether it is expressed in terms of granaticin per unit biomass formed or per unit substrate consumed. The production rate however is more rapid at $37^{\circ} \mathrm{C}$. 


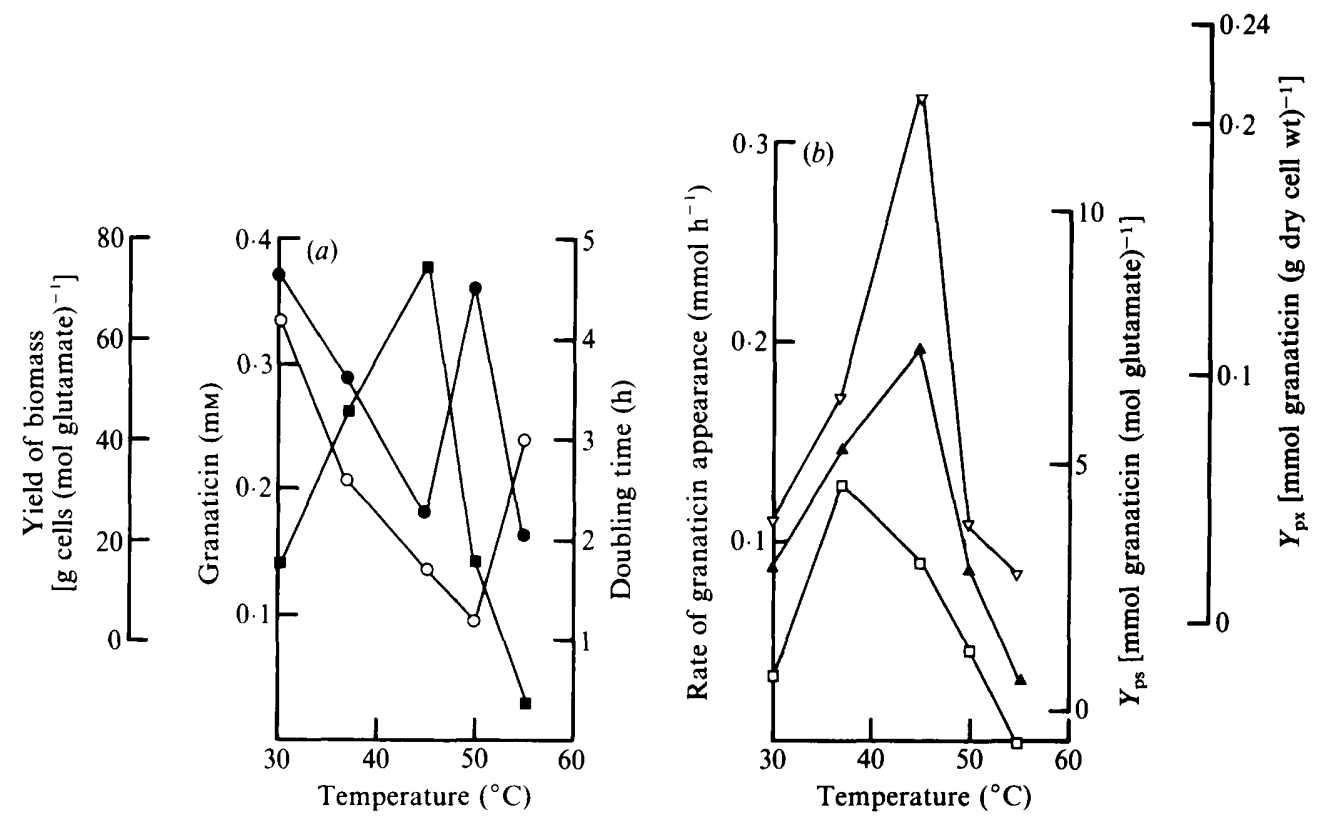

Fig. 3 Summary of the effects of growth temperature on the parameters shown in Fig. 2 for cultures grown in the glutamate salts medium. (a) Biomass yield $(\mathcal{O})$, granaticin yield $(\square)$, and doubling times for growth $(O)$. (b) Rate of granaticin appearance $(\square)$ and the yield of granaticin in terms of carbon source $(\boldsymbol{\Lambda})$ or biomass $(\nabla)$. The results in $(a)$ and $(b)$ are typical of at least two separate experiments.

\section{DISCUSSION}

This work has demonstrated that $S$. thermoviolaceus makes a useful model for studying secondary metabolism and in particular the regulation of a polyketide-derived product. It grows rapidly on a simple salts medium with an appropriate carbon source and produces a coloured and easily quantified antibiotic. Granaticin is preferentially synthesized at temperatures as high as $55^{\circ} \mathrm{C}$ but optimally at $45^{\circ} \mathrm{C}$. This shows that $S$. thermoviolaceus possesses a termotolerant polyketide pathway. Although the rate of production of the secondary metabolite is fastest at $37^{\circ} \mathrm{C}$ the yield is not as high as that seen at $45^{\circ} \mathrm{C}$. We attribute this to a preference for producing biomass at $37^{\circ} \mathrm{C}$ and examination of Fig. $3($ a) shows that there is an inverse relationship between cell yield and titre of antibiotic over the temperature range 30 to $50^{\circ} \mathrm{C}$. What is particularly interesting about the quantities of granaticin produced at the different temperatures is that a preference for biomass rather than granaticin is shown at the two extremes of the temperature range $\left(30\right.$ and $\left.50-55^{\circ} \mathrm{C}\right)$, while at the intermediate temperatures there is a preference for the antibiotic. At $37^{\circ} \mathrm{C}$ there is only $75 \%$ of the quantity of biomass produced at either 30 or $50^{\circ} \mathrm{C}$ whilst there is twice as much antibiotic. At $45^{\circ} \mathrm{C}$ the antibiotic is produced earlier in the fermentation (results not shown) and its synthesis is preferred. At $50^{\circ} \mathrm{C}$, more than at the other temperatures, the commitment is to rapid biomass formation until substrate exhaustion (Fig. $2 b$ ), with a rapid doubling time of $72 \mathrm{~min}$. Earlier work reveals that $S$. thermoviolaceus has a thermosensitive respiratory chain and that there is significant loss of NADH oxidase activity above $40^{\circ} \mathrm{C}$ (Edwards \& Ball, 1987). This would suggest that other factors may also become limiting towards the maximum growth temperature of $58^{\circ} \mathrm{C}$ and would explain slower growth rates with reduced growth yields and low antibiotic titres at $55^{\circ} \mathrm{C}$.

At $30^{\circ} \mathrm{C}$, and to a lesser extent at $50^{\circ} \mathrm{C}$, granaticin is detectable in the culture supernatant before all the glutamate has been utilized. In fact antibiotic synthesis commences up to $1 \mathrm{~h}$ earlier because the cell suspension is always seen to turn blue before granaticin is detectable in the culture supernatant. Therefore, secondary metabolism commences during the period of 
active growth and not when the cells have stopped growing. This is interesting in the light of earlier work suggesting that secondary products are synthesized principally during 'stationary phase' cultures (Demain, 1972; Demain et al., 1979). These reviews also mention that in ideal situations 'trophophase' and 'idiophase' are separate but can overlap in practice. The growth associated antibiotic production reported here is much more in line with findings of workers using continuous culture methods to study the production of antibiotics in the streptomycetes (Siktya et al., 1961; Trilli et al., 1987; Rhodes, 1984) where growth associated antibiotic production could be demonstrated. In some cases as growth rate increased so did antibiotic titre, which suggests that the classification of phases into idio- and trophophase may be misleading.

Measurements of ammoniacal nitrogen show that this parameter mirrors that of antibiotic production, especially at higher temperatures. The fact that increased ammoniacal nitrogen release corresponds to the release of antibiotic and the reduced growth rate would tend to reflect the flux of glutamate-derived carbon and energy through secondary pathways. The synthesis of granaticin when glutamate is used as the sole carbon source is therefore complex and must involve gluconeogenesis in order to provide dideoxyglucose. In addition it may well involve a number of anapleurotic reactions to provide the appropriate glycolytic and Krebs cycle intermediates, in particular either pyruvate or acetyl-CoA for the synthesis.

As noted earlier the doubling time for $S$. thermoviolaceus at $50^{\circ} \mathrm{C}$ is $72 \mathrm{~min}$ which, in addition to the ability to rapidly deplete available substrates, would give the organism a selective advantage in a competitive environment. $S$. thermoviolaceus is isolated readily from horse manure (Desai \& Dhala, 1967) and granaticin has been shown to inhibit RNA synthesis by interference with leucyl-tRNA synthetase in Gram-positive bacteria, notably Bacillus spp. (Ogilvie et al., 1975; Weiser et al., 1977). It could be postulated therefore that if granaticin were synthesized in the environment it would confer a selective advantage for the survival and proliferation of $S$. thermoviolaceus over facultatively thermophilic Bacillus spp. growing in the same environment.

We acknowledge the joint support of the SERC and Glaxo Group Research who funded this CASE award and particularly the valued input of Dr N. Porter and Dr M. J. Dawson.

\section{REFERENCES}

Arnone, A., Camarda, L., Cardillo, R., Fronza, G., Merlini, L., Mondelli, R., Nasini, G. \& ST PYReK, J. (1979). ${ }^{13}$ C-NMR analysis of dihydrogranaticin methyl ester. A case of mixed biogenesis. Helvetica chimica acta 62, 30-34.

Demain, A. L. (1972). Cellular and environmental factors affecting the synthesis and excretion of metabolites. Journal of Applied Chemistry and Biotechnology 22, 345-362.

Demain, A. L., Kennel, Y. M. \& Aharonowitz, Y. (1979). Carbon catabolite regulation of secondary metabolism. Symposia of the Society for General Microbiology 29, 162-185.

Desai, A. J. \& Dhala, D. A. (1967). Streptomyces thermonitrificans sp.n., a thermophilic streptomycete. Antonie van Leeuwenhoek 33, 137-144.

EdWARDS, C. \& Ball, A. S. (1987). Respiratory chain composition and activity in some thermotolerant Streptomyces. FEMS Microbiology Letters 40, 61-66.

Floss, H. G., Cole, S. P., He, X. G., Rudd, B. A. M., Duncan, J., Fujil, I., Chang, C. J. \& Keller, P. (1985). In Regulation of Secondary Metabolism Formation (Workshop Conferences Hoechst 16), pp. 283-304. Edited by H. Kleinkauf, H. Van-Dohren, H. Dornover \& G. Neseman. VCH Verlaggesellschaft.

Goodfellow, M., LACEY, J. \& Todd, C. (1987). Numerical classification of thermophilic streptomycetes. Journal of General Mirobiology 133, 3135-3149.
JAMES, P. D. A. \& EDwards, C. (1988). The effects of cultural conditions on growth and secondary metabolism in Streptomyces thermoviolaceus. FEMS Microbiology Letters 52, 1-6.

Maehr, H., Cuellar, H. V., Smallheer, J., Williams, T. H., SAsso, G. J. \& Berger, J. (1979). Microbial products. II. Granatinic acid, a new antibiotic from a thermophilic streptomycete. Monatsschrift für Chemie 110, 531-540.

Ogilvie, A., Wiebauer, K. \& Kersten, W. (1975). Stringent control of ribonucleic acid synthesis in Bacillus subtilis treated with granaticin. Biochemical Journal 152, 517-522.

RHODES, P. M. (1984). The production of oxytetracycline in chemostat culture. Biotechnology and Bioengineering 26, 382-385.

RUF, F. \& SIEPE, V. (1983). Enzymatic method for the determination of 'free' glutamic acid in soups, sauces and other related products. Alimenta 22, 177-180.

SikTYa, B., Sleazak, J. \& Herold, M. (1961). Growth of Streptomyces aureofaciens in continuous culture. Applied Microbiology 9, 233-238.

Snipes, C. E., Chang, C. J. \& Floss, H. G. (1979). Biosynthesis of the antibiotic granaticin. Journal of the American Chemical Society 101, 701-706.

St Pyrek, J., Mordarski, M. \& Zamojski, A. (1969). Identification of antibiotic WR 141. Archivum immunologiae et therapiae experimentalis 17, 827832. 
Trilli, A., Crossey, M. V. \& Kontakou, M. (1987). Relation between growth rate and erythromycin production in Streptomyces erythraeus. Biotechnology Letters 9, 765-770.

VU-Trong, K. \& Gray, P. P. (1987). Influence of ammonia on the biosynthesis of the macrolide antibiotic tylosin. Enzyme and Microbial Technology 9, 590-593.

Wainwright, M. \& PUGH, G. J. F. (1973). The effect of three fungicides on nitrification and ammonification in soil. Soil Biology and Biochemistry 5, 577-584.
Weiser, J., JANDA, K., MikULIK, K. \& TAX, J. (1977). Interaction of granaticin B with the transcription system of Bacillus subtilis. Folia microbiologica 22, 329-338.

Williams, S. T., Goodfellow, M., Wellington, E. M. H., SNeath, P. H. \& Sackin, M. J. (1983). Numerical classification of Streptomyces and related genera. Journal of General Microbiology 129, 17431813. 